\title{
Effect of Blasting During Tunnel Excavation on an Existing Adjacent Tunnel
}

\author{
Van Kien DANG ${ }^{1}$ \\ Trong Hung $\mathrm{VO}^{2}$
}

\begin{abstract}
In recent decades, the effects of blast loads on existing structures have gained considerable attention due to the increase in threat from various activities. Site-specific empirical relationships for calculation of blast-induced vibration parameters like Peak Particle Velocity (PPV), Peak Particle Acceleration (PPA), and Peak Particle Displacement (PPD) are commonly used for the estimation of the impact of blasting vibration on an existing adjacent tunnel. However, these relationships are not able to consider the variation in rock parameters and uncertainty of in situ conditions such as modern rock mass classifications (i.e., RMR, Qsystem, RQD). In this paper, a published blast data of various researchers in different rock sites at Croix-Rousse tunnel in France have been collected and used to propose a generalized regression model for PPV by considering the effects of rock parameters like Rock Mass Rating (RMR) system, damping ratio “ $\xi$ ”, Dynamic Young's modulus “ $E_{d}$ ”. By using the numerical analysis method, the proposed regression model of PPV (Empirical Formula) function of a variable and multivariate can be directly used in the prediction of blast-induced vibrations in rocks.
\end{abstract}

Keywords: PPV, blasting vibration, multivariate equations, RMR, twin tunnels.

\section{INTRODUCTION}

An important consideration for tunnel excavation in urban areas using the drilling and blasting method is to avoid damage to existing buildings and structures as this method generates ground vibrations. Nowadays, many parameters are used to estimate blast-induced vibration as particle velocity and particle acceleration, particle displacement... However, particle velocity is the most suitable parameter for assessing vibration-associated risks. The particle velocity is also used for most standards in the world because it can be measured by Geophone sensors. The amplitude of blast-induced vibrations and the PPV are influenced by the type of

Note:

- This paper was received on September 30, 2021 and accepted for publication by the Editorial Board on January 7, 2022.

- Discussions on this paper will be accepted by November 30, 2022.

- https://doi.org/10.18400/tekderg.1002681

1 Faculty of Civil Engineering, Hanoi University of Mining and Geology, Hanoi, Vietnam dangvankien@humg.edu.vn - https://orcid.org/0000-0001-8821-9178

2 Faculty of Civil Engineering, Hanoi University of Mining and Geology, Hanoi, Vietnam votronghung@humg.edu.vn - https://orcid.org/0000-0001-5923-5806 
explosives used and the charge weight per delay and the distance between the blast face and the monitoring point, as well as geological and geotechnical conditions of the rock units in the excavation area. Different methods have been suggested to evaluate the ground vibrations level during blasting such as: the in-situ measurement based on sensors, the empirical approach model, the numerical simulation model ... The parameter values of rock mass is available in tunneling projects. It is very effective to find out the rule between PPV and parameter values of rock mass quality such as RMR, Q, RQD. By this relation, it allows quick and efficient determination of PPV values according to rock mass parameters. However, up to now, there has not been a scientific work to effectively propose the relationship between PPV and rock mass parameters.

In tunneling, the use of concrete is often restricted near the area where blasting takes place, due to the risk of vibration damage. An important example is the driving of two parallel tunnels that requires coordination between the two excavations so that blasting in one tunnel does not, through vibrations, damage temporary support systems in the other tunnel prior to installation of robust, permanent support, see Figure 1.

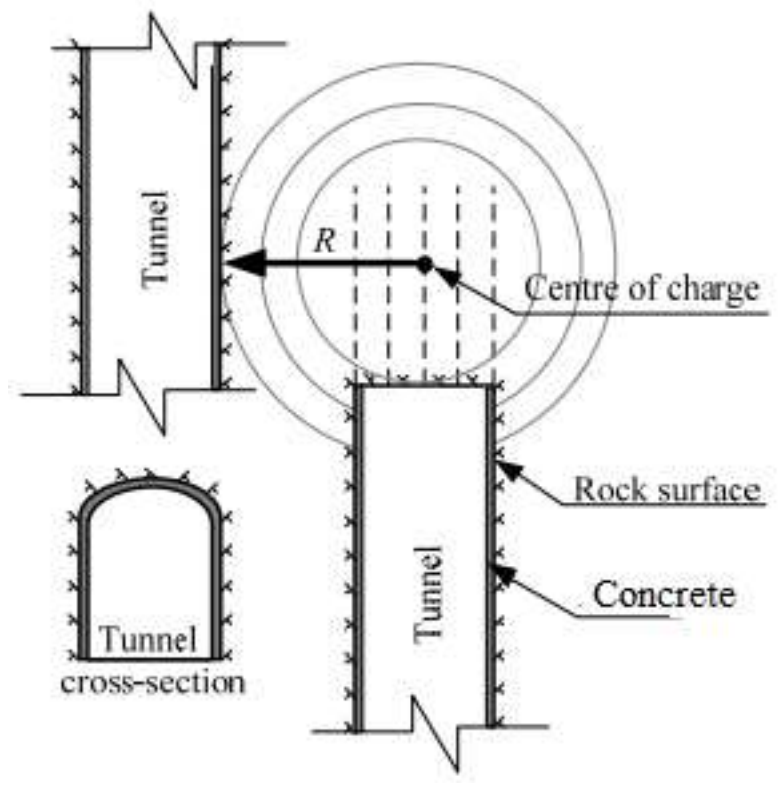

Figure 1 - Construction of two parallel tunnels [2]

Based on the measurement data and numerical model available at the Croix-Rousse tunnel project, Lyon, France, the paper was carried out to build the relationship between PPV and parameters based on numerical methods. It allows quick determination of the PPV value under the same conditions as the Croix-Rousse tunnel. This study was carried out determination the relationship between PPV and parameters based on numerical methods.

The Croix-Rousse tunnel is located in Lyon, France, between the Rhône and the Saone rivers. The length of the tunnel is $1757 \mathrm{~m}$ with a cross-section area of $84.10 \mathrm{~m}^{2}$. A new tunnel was 
excavated in parallel to the existing one. The distance wall to wall between these two tunnels is around $29.27 \mathrm{~m}$ (Figure 2). The cover depth of the tunnels varies between 70 and $100 \mathrm{~m}[1]$.

In addition, some authors also studied the impact of blasting on existing tunnel structure such as following cases: The effect of an internal explosion in a tunnel on a neighboring buried tunnel and free surface [1]; the impact of the explosion which is placed on the ground to the tunnels; the impact of a bomb explosion at the surface on fortifications [7], [11]. The paper was used the measuring results at Croix-Rousse tunnel project, Lyon, France to study to establish empirical (regression function) between PPV and parameters according to many criteria simultaneous influences (multiple variables). Characteristics of the Croix-Rousse tunnel project were introduced in articles $[4] \div[6]$.

The blasting vibrations induced in the existing tunnel during the excavation of the new CroixRousse tunnel were monitored using sensors of the Geophone type. The sensors (A, P, and T as seen in Fig.3) were embedded in the concrete lining along the tunnel axis. Results of the PPV values are monitored in three directions, including transverse direction, vertical direction, and the longitudinal direction of the tunnel. The maximum value of the three orthogonal components $(\mathrm{x}, \mathrm{y}, \mathrm{z})$ is presented in Table 1 [13].

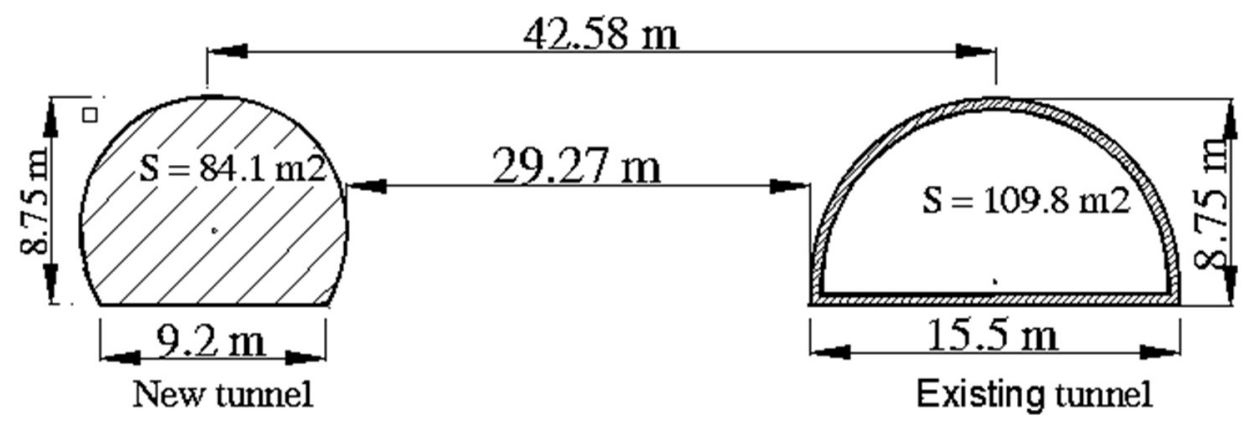

Figure 2 - Construction of two parallel tunnels in Croix-Rousse tunnel, Lyon, France

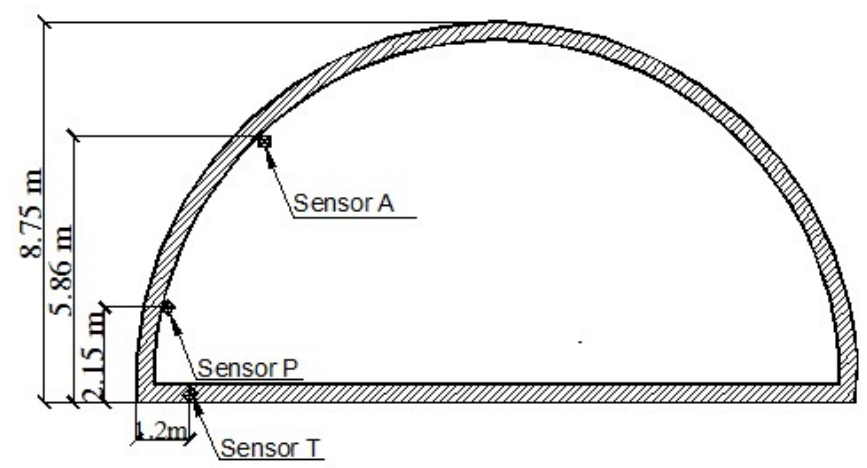

Figure 3 - Location of sensors in the existing tunnel at Croix-Rousse tunnel 
Impact of blasting at tunnel face on an existing adjacent tunnel at Croix-Rousse tunnel was performed using the Finite Element Method with the Abaqus/Explicit 6.11-2 software by 2D and 3D model by author. The result of research by numerical models shows the relation between PPV (mm/s) on damping ratio " $\xi$ ", dynamic Young's modulus " $E_{d}$ ", and time " $\mathrm{t}$ " (s) such as Table $3 \div$ Table 6 [12].

Table 1 - Monitoring data of blasting velocity

\begin{tabular}{|c|c|c|}
\hline Order number of blasting & Explosion weight: $\mathbf{Q}_{\max }(\mathbf{k g})$ & PPV $_{\max }(\mathbf{m m} / \mathbf{s})$ \\
\hline 230 & 544.0 & 3.58 \\
\hline 231 & 574.5 & 8.99 \\
\hline 232 & 647.0 & 12.12 \\
\hline 233 & 662.0 & 15.36 \\
\hline 234 & 1153.0 & 14.59 \\
\hline 235 & 870.0 & 10.08 \\
\hline 236 & 871.0 & 7.21 \\
\hline 239 & 849.0 & 5.69 \\
\hline
\end{tabular}

\section{SOME MEASURING RESULTS AT CROIX-ROUSSE, LYON, FRANCE}

Based on the measuring data at Croix-Rousse tunnel by sensors in the existing tunnel, multivariate equations estimated to present a relation between PPV $(\mathrm{mm} / \mathrm{s})$ and damping ratio " $\xi$ ", time " $t$ " (s) at Table 2 . The multivariate equations are estimated to present the relation between the PPV $(\mathrm{mm} / \mathrm{s})$ on " $E_{d}$ " and " $t$ " (s) in Table 3.

Table 2 - PPV value $(\mathrm{mm} / \mathrm{s})$ depends on damping ratio “ $\xi$ ” and time " $t$ ” (s)

\begin{tabular}{|c|c|c|c|c|c|c|c|c|c|}
\hline \multicolumn{1}{l}{ t(s) } \\
\hline & $\begin{array}{c}\text { Field } \\
\text { data }\end{array}$ & $\xi=\mathbf{3} \%$ & $\Delta, \%$ & $\xi=\mathbf{4} \%$ & $\Delta, \%$ & $\xi=5 \%$ & $\Delta, \%$ & $\xi=6 \%$ & $\Delta, \%$ \\
\hline 0.0064 & 9.23 & 16.54 & 44.22 & 13.50 & 31.67 & 11.42 & 19.19 & 9.89 & 6.71 \\
\hline 0.033 & 7.17 & 15.75 & 54.44 & 12.65 & 43.26 & 10.61 & 32.39 & 9.08 & 20.99 \\
\hline 0.061 & 9.52 & 15.27 & 37.65 & 11.99 & 20.61 & 9.81 & 2.980 & 8.32 & 14.42 \\
\hline 0.163 & 10.10 & 14.66 & 31.11 & 11.30 & 10.62 & 9.16 & 10.20 & 7.71 & 30.98 \\
\hline 0.264 & 8.05 & 17.08 & 52.82 & 14.96 & 46.17 & 12.58 & 35.97 & 10.92 & 26.21 \\
\hline 0.366 & 12.16 & 18.75 & 35.15 & 14.70 & 17.29 & 12.40 & 1.980 & 10.58 & 14.91 \\
\hline 0.568 & 9.81 & 15.78 & 37.81 & 14.59 & 32.75 & 13.17 & 25.50 & 11.34 & 13.45 \\
\hline 0.771 & 10.24 & 17.35 & 40.97 & 13.546 & 24.36 & 10.298 & 0.500 & 8.348 & 22.74 \\
\hline
\end{tabular}

Note: $\Delta \%$ - The difference between field data and numerical result 
Table 3 - PPV value depends on " $E_{d}$ " and " $t$ ” (s)

\begin{tabular}{|c|c|c|c|c|c|c|c|c|c|}
\hline t(s) & \multicolumn{10}{c}{ Giá trị PPV $(\mathbf{m m} / \mathbf{s}) \mathbf{w i t h} \mathbf{E}_{\mathbf{d}}(\mathbf{G P a})$} \\
\hline & $\begin{array}{c}\text { Field } \\
\text { data }\end{array}$ & $\begin{array}{c}\mathbf{E}_{\mathbf{d}}=\mathbf{4 0} \\
\mathbf{G P a}\end{array}$ & $\Delta, \boldsymbol{\%}$ & $\begin{array}{c}\mathbf{E}_{\mathbf{d}}=\mathbf{5 0} \\
\mathbf{G P a}\end{array}$ & $\Delta, \%$ & $\begin{array}{c}\mathbf{E}_{\mathbf{d}}=\mathbf{6 0} \\
\mathbf{G P a}\end{array}$ & $\Delta, \%$ & $\begin{array}{c}\mathbf{E}_{\mathbf{d}}=\mathbf{7 0} \\
\mathbf{G P a}\end{array}$ & $\Delta, \%$ \\
\hline 0.0064 & 9.23 & 5.84 & 36.72 & 11.72 & 21.24 & 11.42 & 19.18 & 9.63 & 4.15 \\
\hline 0.033 & 7.17 & 7.22 & 0.69 & 12.386 & 42.11 & 10.61 & 32.42 & 8.5 & 15.65 \\
\hline 0.061 & 9.52 & 9.7 & 1.86 & 12.48 & 23.72 & 9.81 & 2.96 & 7.43 & 28.13 \\
\hline 0.163 & 10.10 & 13.8 & 26.81 & 12.56 & 19.59 & 9.16 & 10.26 & 6.5 & 35.64 \\
\hline 0.264 & 8.05 & 1.23 & 84.72 & 9.7 & 17.01 & 12.58 & 36.01 & 11.29 & 28.69 \\
\hline 0.366 & 12.16 & 4.16 & 65.79 & 13.1 & 7.18 & 12.4 & 1.94 & 10.3 & 15.29 \\
\hline 0.568 & 9.81 & -0.047 & 100.48 & 8.36 & 14.78 & 13.17 & 25.51 & 11.85 & 17.21 \\
\hline 0.771 & 10.24 & 14.73 & 30.48 & 14.41 & 28.94 & 10.29 & 0.49 & 7.73 & 24.51 \\
\hline
\end{tabular}

Note: $\Delta \%$ - The difference between field data and numerical result

Based on field data in Table 4, the depends on PPV on Damping " $\xi$ " and "t" (s) and the depends on PPV "E $E_{d}$ " (GPa) and "t" (s) are given such as on at Table 4 and Table 5.

Table 4 - PPV value depends on Damping “ $\xi$ ” and " $t$ ” (s)

\begin{tabular}{|c|c|c|c|}
\hline № & $\mathbf{P P V}(\mathbf{m m} / \mathbf{s})$ & $\mathbf{t}(\mathbf{s})$ & $\xi(\mathbf{\%})$ \\
\hline 1 & 16.54 & 0.0064 & 3.0 \\
\hline 2 & 15.75 & 0.033 & 3.0 \\
\hline 3 & 15.27 & 0.061 & 3.0 \\
\hline 4 & 14.66 & 0.163 & 3.0 \\
\hline 5 & 17.08 & 0.264 & 3.0 \\
\hline 6 & 18.75 & 0.366 & 3.0 \\
\hline 7 & 15.78 & 0.568 & 3.0 \\
\hline 8 & 17.35 & 0.771 & 3.0 \\
\hline 9 & 13.50 & 0.0064 & 4.0 \\
\hline 10 & 12.65 & 0.033 & 4.0 \\
\hline 11 & 11.99 & 0.061 & 4.0 \\
\hline 12 & 11.30 & 0.163 & 4.0 \\
\hline 13 & 14.96 & 0.264 & 4.0 \\
\hline 14 & 14.70 & 0.366 & 4.0 \\
\hline 15 & 14.59 & 0.568 & 4.0 \\
\hline 16 & 13.546 & 0.771 & 4.0 \\
\hline 17 & 11.42 & 0.0064 & 5.0 \\
\hline 18 & 10.61 & 0.033 & 5.0 \\
\hline
\end{tabular}


Table 4 - PPV value depends on Damping “ $\xi$ ” and " $t$ " (s) (continue)

\begin{tabular}{|c|c|c|c|}
\hline № & PPV (mm/s) & $\mathbf{t}(\mathbf{s})$ & $\xi(\mathbf{\%})$ \\
\hline 19 & 9.81 & 0.061 & 5.0 \\
\hline 20 & 9.16 & 0.163 & 5.0 \\
\hline 21 & 12.58 & 0.264 & 5.0 \\
\hline 22 & 12.4 & 0.366 & 5.0 \\
\hline 23 & 13.17 & 0.568 & 5.0 \\
\hline 24 & 10.29 & 0.771 & 5.0 \\
\hline 25 & 9.63 & 0.0064 & 6.0 \\
\hline 26 & 8.50 & 0.033 & 6.0 \\
\hline 27 & 7.43 & 0.061 & 6.0 \\
\hline 28 & 6.50 & 0.163 & 6.0 \\
\hline 29 & 11.29 & 0.264 & 6.0 \\
\hline 30 & 10.30 & 0.366 & 6.0 \\
\hline 31 & 11.85 & 0.568 & 6.0 \\
\hline 32 & 7.73 & 0.771 & 6.0 \\
\hline
\end{tabular}

Table 5 - PPV value depends on " $E_{d}$ " (GPa) and " $t$ " (s)

\begin{tabular}{|c|c|c|c|}
\hline № & $\mathbf{P P V}(\mathbf{m m} / \mathbf{s})$ & $\mathbf{t}(\mathbf{s})$ & $\mathbf{E}_{\mathbf{d}}(\mathbf{G P a})$ \\
\hline 1 & 5.84 & 0.0064 & 40.0 \\
\hline 2 & 7.22 & 0.033 & 40.0 \\
\hline 3 & 9.70 & 0.061 & 40.0 \\
\hline 4 & 13.8 & 0.163 & 40.0 \\
\hline 5 & 1.23 & 0.264 & 40.0 \\
\hline 6 & 4.16 & 0.366 & 40.0 \\
\hline 7 & 14.73 & 0.771 & 40.0 \\
\hline 8 & 11.72 & 0.0064 & 50.0 \\
\hline 9 & 12.386 & 0.033 & 50.0 \\
\hline 10 & 12.48 & 0.061 & 50.0 \\
\hline 11 & 12.56 & 0.163 & 50.0 \\
\hline 12 & 9.70 & 0.264 & 50.0 \\
\hline 13 & 13.1 & 0.366 & 50.0 \\
\hline 14 & 8.36 & 0.568 & 50.0 \\
\hline 15 & 14.41 & 0.771 & 50.0 \\
\hline 16 & 11.42 & 0.0064 & 60.0 \\
\hline 17 & 10.61 & 0.033 & 60.0 \\
\hline 18 & 9.81 & 0.061 & 60.0 \\
\hline
\end{tabular}


Table 5 - PPV value depends on " $E_{d}$ " (GPa) and " $t$ " (s) (continue)

\begin{tabular}{|c|c|c|c|}
\hline № & PPV (mm/s) & $\mathbf{t}(\mathbf{s})$ & $\mathbf{E}_{\mathbf{d}}(\mathbf{G P a})$ \\
\hline 19 & 9.16 & 0.163 & 60.0 \\
\hline 20 & 12.58 & 0.264 & 60.0 \\
\hline 21 & 12.4 & 0.366 & 60.0 \\
\hline 22 & 13.17 & 0.568 & 60.0 \\
\hline 23 & 10.29 & 0.771 & 60.0 \\
\hline 24 & 9.63 & 0.0064 & 70.0 \\
\hline 25 & 8.50 & 0.033 & 70.0 \\
\hline 26 & 7.43 & 0.061 & 70.0 \\
\hline 27 & 6.50 & 0.163 & 70.0 \\
\hline 28 & 11.29 & 0.264 & 70.0 \\
\hline 29 & 10.3 & 0.366 & 70.0 \\
\hline 30 & 11.85 & 0.568 & 70.0 \\
\hline 31 & 7.73 & 0.771 & 70.0 \\
\hline
\end{tabular}

\section{STUDY TO DETERMINE REGRESSION MODEL BY A FUNCTION OF A VARIABLE PPV = F (RMR)}

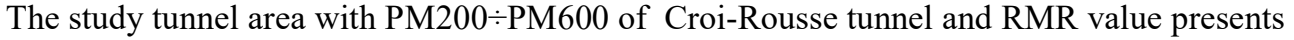
Figure 4 and Table 6 . Inconsistent measurement results from sensors will be removed before finding the relationship between the parameters " $K$ ", " $\alpha$ " (in Chapot's formula), and the "RMR" value of the rock mass. Using a formula of Chapot (1980) (1) in the French standards are often used to investigate o the relation between the (PPV) and $\mathrm{S}_{\mathrm{D}}, S_{D}=\left(\frac{D}{\sqrt{Q_{c}}}\right)^{-\alpha}$ :

$$
P P V=K \cdot\left(\frac{D}{\sqrt{Q_{c}}}\right)^{-\alpha} \quad(\text { Chapot 1980) }
$$

PPV- Pick Particle Velocity ( $\mathrm{mm} / \mathrm{s})$; D - is the distance from the blasting source to the point of monitoring $(\mathrm{m}) ; \mathrm{Q}_{\mathrm{c}}$ - is the maximum charge weight per delay $(\mathrm{kg}) ; \mathrm{K}$ and $\alpha$ are constants that depend on the ground condition as well as the conditions of blasting;

Analysis of recording vibrations in the Croix-Rousse tunnel by using the recording result at sensor A or sensor P (Figure 3). We can find the relation Relation between the maximum value of (PPV) and scaled charge explosive $S_{D}$ in sensor $P$. The layout of the two tunnels is presented in Figure.5. H represents the distance from the section in the existing tunnel to the tunnel face of the new tunnel. The numerical results indicate that the biggest particle velocity induced in the tunnel lining of the existing tunnel is obtained when the section is closer to the blasting location (the case of $\mathrm{H}=0$ in Figure.5). By analyzing the measurement data obtained from the sensor P, paper is obtained a relationship between " $\mathrm{Ln}(\mathrm{K})$ " and " $\alpha$ " in the Chapot formula with "RMR" value is described on Figure 6. 


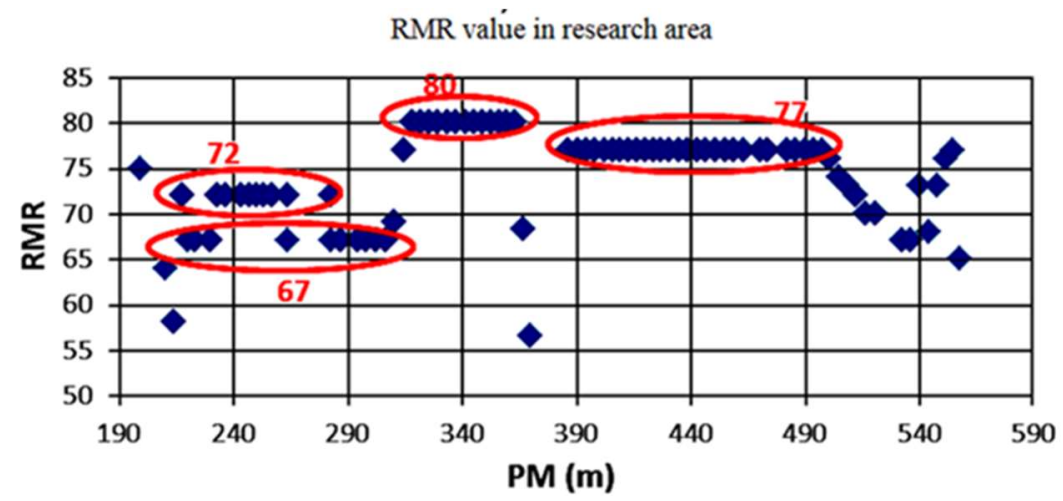

Figure 4 - RMR value in the research area

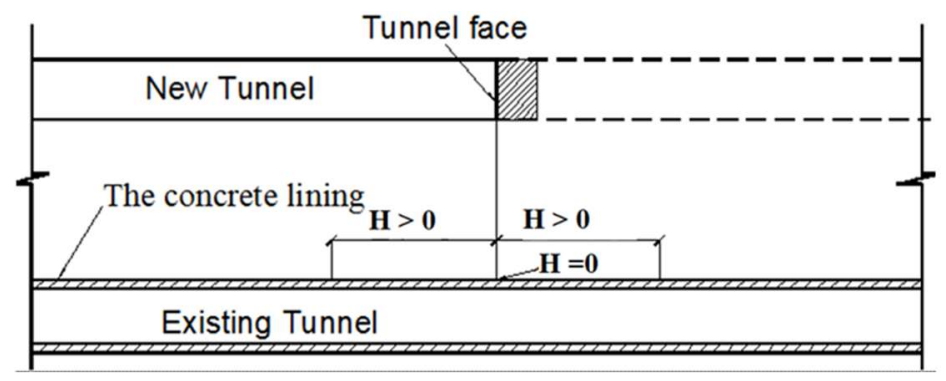

Figure 5 - Layout of two tunnels

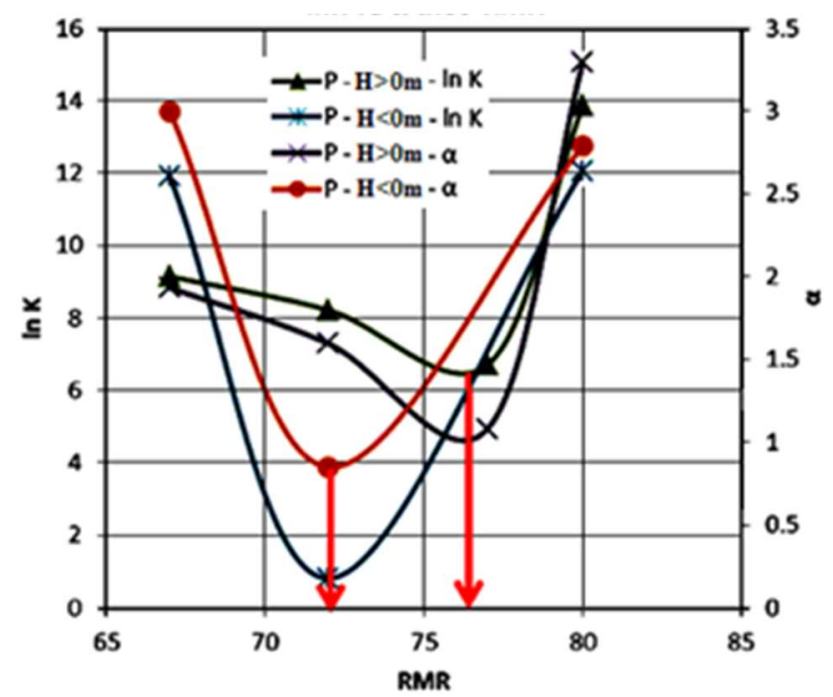

Figure 6 - Relationship between "Ln (K)" and " $\alpha$ " in the Chapot formula with "RMR" value at sensor $P$ 
By using the measuring value of sensor P at Croix- Rousse tunnel, the relation between PPV and RMR is established for granite rock with the function of a variable obtained formula (2). A flowchart in this study of the determined regression model functions using different types of regression is presented in Figure 7.

Table 6 - Location of the research areas in the tunnel

\begin{tabular}{|c|c|c|c|c|}
\hline $\begin{array}{c}\text { Research } \\
\text { Areas }\end{array}$ & From KP & To KP & $\begin{array}{c}\text { Length of research } \\
\text { area, m }\end{array}$ & Rock type \\
\hline 1 & 200 & 600 & 400 & Granit \\
\hline 2 & 640 & 750 & 110 & Gơnai \\
\hline 3 & 750 & 1430 & 680 & Granit \\
\hline
\end{tabular}

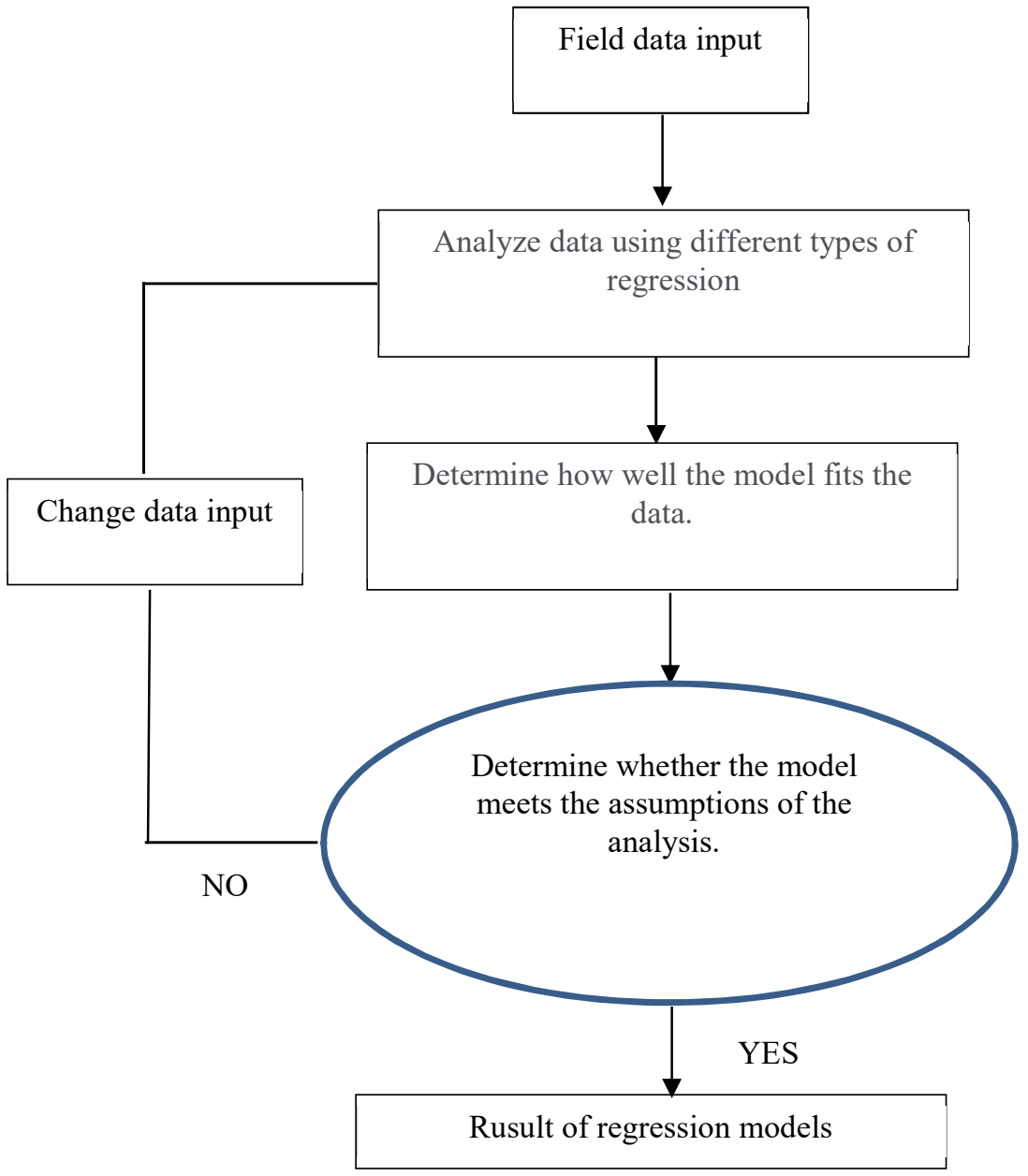

Figure 7 - Flowchart of the determine regression model functions 
By using the measuring value of sensor P, the relation between PPV and RMR is established for granite rock with the function of a variable obtained formula (2):

$$
P P V=\left(7 \cdot 10^{8} \cdot e^{-0,171 \cdot R M R}\right) \cdot(D / \sqrt{Q})^{-\left(\begin{array}{l}
2.4991 . R M^{3}-53.79 R M M^{2}+ \\
+38736 \cdot R M R-921961
\end{array}\right)}
$$

Although it is the function of a variable, but it is very useful to give so fast PPV value based on the actual value RMR of surrounding rock mass conditions. It also is a good trend to continue studies on this problem in the future.

\section{STUDY TO DETERMINE REGRESSION MODEL BY FUNCTION OF TWO VARIABLES PPV $=\mathbf{F}(t, \xi)$}

After using the output data of Table 3, PPV value depends on " $t$ " (s) and " $\zeta$ " obtained program found multi-variable experimental functions in Pascal programming language. The result has given 9 regression models (Empirical Formula) of two variables $P P V=F(t, \zeta)$ such as:

Regression model (Empirical Formula) first:

$$
P P V=22.79+1.86-2.39 \times \xi ; \quad \mathrm{R}=0,89 ;
$$

Regression model (Empirical Formula) second:

$P P V=44.22 \times(T)^{(0.019)} \times(\xi)^{(-0.85)} ; \quad \mathrm{R}=0.86 ;$

Regression model (Empirical Formula) third:

$$
P P V=28.34+0.25 \times \operatorname{Ln}(T)-10.39 \times \operatorname{Ln}(\xi) ; \quad \mathrm{R}=0.89 ;
$$

Regression model (Empirical Formula) fourth:

$$
P P V=e^{(28.43+0.15 \times T-0.19 \times \xi)} ; \quad \mathrm{R}=0.87 ;
$$

Regression model (Empirical Formula) fifth:

$P P V=2.42-0.00037 \times(1 / T)+42.58 \times(1 / \xi) ; \quad \mathrm{R}=0.87 ;$

Regression model (Empirical Formula) sixth:

$$
P P V=30.83 \times(T)^{(0.019)} \times e^{(-0.19 \times \xi)} ; \quad \mathrm{R}=0.86 ;
$$

Regression model (Empirical Formula) seventh:

$$
P P V=40.79 \times(e)^{[(0.15) \times T]} \times(\xi)^{(-0.85)} ; \quad \mathrm{R}=0.86 ;
$$

Regression model (Empirical Formula) eighth:

$$
P P V=40.79 \times(e)^{[(0.15) \times T]} \times(\xi)^{(-0.85)} ; \quad \mathrm{R}=0.86 ;
$$

Regression model (Empirical Formula) ninth:

$$
P P V=(30.82) \times(T)^{(0.019)} \times e^{[(-0.19) \times \xi]} ; \quad \mathrm{R}=0.86
$$

Where: F - type of regression model (empirical formula); PPV - Peak Particle Velocity; T time; $\xi$ - damping value; $\mathrm{R}$ - multiples correlation coefficient. 
After comparing the multiples' correlation coefficient of regression model (empirical formula) (2),(10), the biggest of multiples correlation coefficient obtained with regression model second, $\mathrm{R}=0,89$. This regression model can be the original model to determine "The largest amount of explosives for one explosion" on the actual condition.

\section{STUDY TO DETERMINE REGRESSION MODEL FUNCTION OF TWO VARIABLES PPV $=F\left(t, E_{d}\right)$}

After using output data of Table 4, PPV value depends on " $E_{d}$ " and " $t$ "(s) obtained program found multi-variable experimental functions in Pascal programming language. The result has given 9 regression models (Empirical Formula) of two variables $P P V=F\left(t, E_{d}\right)$ such as.

Regression model (Empirical Formula) first:

$$
P P V=(6.45+1.06 x T+0.055 X E ; \quad \mathrm{R}=0,196 ;
$$

Regression model (Empirical Formula) second:

$P P V=1,041 \times(T)^{(0,008698489)} \times(E)^{(0,554901612)} ; \quad \mathrm{R}=0,24 ;$

Regression model (Empirical Formula) third:

$$
P P V=64,39+0,25 \times \operatorname{Ln}(T)-12,88 \times \operatorname{Ln}(E) ; \quad \mathrm{R}=0,89 ;
$$

Regression model (Empirical Formula) fourth:

$P P V=e^{(6,008417125+, 210416129 \times T+0,085759656 \times E)} ; \quad \mathrm{R}=0,238 ;$

Regression model (Empirical Formula) fifth:

$P P V=-0,124-0,00036 \times(1 / T)+667,19 \times(1 / E) ; \mathrm{R}=0,88 ;$

Regression model (Empirical Formula) sixth:

$$
P P V=6,42 \times(T)^{(0,0093)} \times(e)^{[(0,087) \times E]} ; \quad \mathrm{R}=0,21 ;
$$

Regression model (Empirical Formula) seventh:

$$
P P V=1,0113 \times(e)^{[(0,2055) \times T]} \times(E)^{(0,543)} ; \quad \mathrm{R}=0,270 ;
$$

Regression model (Empirical Formula) eighth:

$$
P P V=6,0084 \times(e)^{[(0,2104) \times T]} \times(e)^{[(0,085) \times E]} ; \quad \mathrm{R}=0,23
$$

Regression model (Empirical Formula) ninth:

$$
P P V=(6,427) \times(T)^{(0,0093)} \times e^{[(0,087) \times E]} ; \quad \mathrm{R}=211 ;
$$

Where: F - the type of regression model (empirical formula); PPV- Peak Particle Velocity; T - time (s); E $\mathrm{d}_{\mathrm{d}}$ Dynamic Young's modulus of rock mass; R - multiples correlation coefficient.

After comparing the multiples' correlation coefficient of regression model (empirical formula) $(11) \div(19)$, the biggest of multiples correlation coefficients obtained with regression model in equation (13), $\mathrm{R}=0,89$. This regression model can be the original model to determine "The largest amount of explosives for one explosion" on the actual condition. 
Received results also show that in the practice when building new tunnels near the existing tunnel to reduce effects of vibration of blasting can be predicted PPV value based on the Dynamic Young's modulus $\left(E_{d}\right)$ of rock mass and time $(t)$. Comparing the value of the calculated PPV value with the corresponding allowed value of the standards can indicate rocks mass and tunnel lining works have stabilized under the effect of blasting load.

\section{STUDY TO DETERMINE REGRESSION MODEL WITH FUNCTIONS OF THREE VARIABLES}

According to the above results, after using field data at Croix-Rousse, Lyon, France on Table $2 \div$ Table 5, the effect of PPV on three parameters: " $\xi$ " and " $t$ " and " $E_{d}$ " is present in Table 5 .

Table 5 - PPV value depends on three parameters " $\xi$ " and " $t$ " and " $E_{d}$ "

\begin{tabular}{|c|c|c|c|c|c|}
\hline \multicolumn{1}{c}{ № } & \multicolumn{1}{c}{ PPV } & \multicolumn{1}{c}{ T } & \multicolumn{1}{c}{ E } & \multicolumn{1}{c}{$\xi$} & H \\
\hline 1 & 11.72 & 0.0064 & 50.0 & 5.0 & 0 \\
\hline 2 & 11.3 & 0.163 & 70.0 & 4.0 & 0 \\
\hline 3 & 10.61 & 0.033 & 60.0 & 5.0 & 0 \\
\hline 4 & 8.32 & 0.061 & 50.0 & 6.0 & 0 \\
\hline 5 & 7.73 & 0.771 & 70.0 & 6.0 & 0 \\
\hline 6 & 7.43 & 0.061 & 70.0 & 6.0 & 0 \\
\hline
\end{tabular}

After using the output data of Table 5, a program found multi-variable experimental functions in the Pascal programming language. The result has given 9 regression models (Empirical Formula) of the following three variables function:

$$
\mathrm{PPV}=\mathrm{F}\left(\mathrm{t}, \mathrm{E}_{\mathrm{d}}, \xi\right)
$$

Regression model (Empirical Formula) first:

$P P V=26.49+0.48 \times T-0.086 x E-2.197 x \xi ; \quad \mathrm{R}=0,97 ;$

Regression model (Empirical Formula) second:

$P P V=5,47 \times(T)^{(-0,024317111)} \times(E)^{(-0,37108331)} \times(\xi)^{(-1,072039643)} ; \quad \mathrm{R}=0.96 ;$

Regression model (Empirical Formula) third:

$P P V=38,05-0,269 \times \operatorname{Ln}(T)-3,076 \times \operatorname{Ln}(E)-9,98 \times \operatorname{Ln}(\xi) ; \quad \mathrm{R}=0.97 ;$

Regression model (Empirical Formula) fourth:

$P P V=e^{(4,061958308+, 056244176 \times T-0,009530558 \times E-0,234058115 \times \xi)} ; \quad \mathrm{R}=0.97 ;$

Regression model (Empirical Formula) fifth:

$P P V=-2,33+0,012 \times(1 / T)+140,88 \times(1 / E)+47,31 \times(1 / \xi) ; \quad \mathrm{R}=0.97 ;$ 
Regression model (Empirical Formula) sixth:

$P P V=4,35 \times(T)^{(-0,023100363)} \times(e)^{[(-0,006446419) \times E]} \times(x)^{(-1,073281227)} ; \mathrm{R}=0.96 ;$

Regression model (Empirical Formula) seventh:

$P P V=4,89 \times(T)^{(-0,018614246)} \times(E)^{(-0,376230868)} \times(e)^{[(-0,217764272) \times \xi]} ; \mathrm{R}=0.97 ;$

Regression model (Empirical Formula) eighth:

$P P V=6,57 \times(e)^{[(0,042906918) \times T]} \times(E)^{(-0,589078741)} \times(\xi)^{(-1,159819879)} ; \quad \mathrm{R}=0.96 ;$

Regression model (Empirical Formula) ninth:

$P P V=4,77 \times(e)^{[(0,048844617) \times T]} \times(e)^{[(-0,010078617) \times E]} \times(\xi)^{(-1,160663177)} ; \mathrm{R}=0.96 ;$

Regression model (Empirical Formula) tenth:

$P P V=5,77 \times(e)^{[(0,051432765) \times T]} \times(E)^{(-0,55901163)} \times(e)^{[(-0,234192886) \times \xi]} ; \quad \mathrm{R}=0.97$

Regression model (Empirical Formula) eleventh:

$P P V=(3,75) \times(T)^{(-0,017619142)} \times e^{[(-0,006486009) \times E]} \times e^{[(-0,217789924) \times \xi]} ; \mathrm{R}=0.97$

Where: $\mathrm{F}$ - the type of regression model (empirical formula); PPV- Peak Particle Velocity; T-time (s); $E_{d}$ - Dynamic Young's modulus of rock mass; $\xi$ - damping value in the numerical model; R - multiples correlation coefficient.

After comparing the multiples' correlation coefficient of the regression model (empirical equation (20) to equation (30)), the biggest of multiples correlation coefficients obtained with regression model in equation (30), $\mathrm{R}=0,97$. This regression model can be an original model to determine "The largest amount of explosives for one explosion" on the actual condition. The above results show that using the result of numerical models with the field data investigations on the effect of the blasting in a new tunnel on the surrounding rock mass and on the existing tunnel can be carried out by regression model. The research results show that not only predicting the tunnel lining damage zone under the impact of blast loads but also determination peak maximum of explosion at the same time at the tunnel face by equation (1).

\section{CONCLUSION}

By obtained result in this study, several conclusions can be drawn as follows:

PPV value is dependent on many different parameters such as physical-mechanics properties of the rock around the blasting area $\left(\mathrm{E}_{\mathrm{d}}\right.$-Dynamic Young's modulus; $\xi$-damping value, $\mathrm{t}$ - time at the investigated point from the time of blasting, $\mathrm{H}$-the distance from an investigated point to explosion point and some parameters).

The first time, the relation between PPV and RMR is established for granite rock with the function of a variable in the Croix-Rousse tunnel by equation (2). Although this equation is the function of a variable, it is useful to give so fast PPV value based on the actual value RMR of projects the same conditions as the Croix-Rousse tunnel. It is a result to applied in equivalent conditions and also a new direction to study in the future. 
Paper was also carried out to investigate the PPV value on above some parameters and to establish regression models thought the relation between PPV and effect parameters by a function of two variables such as equation (2) to equation (19). The PPV value also is a function of three variables of dependent parameters such as equation (20) to equation (30). However, PPV is a function of multivariate so reflection on the effect of all the actual conditions on PPV value is not fully. So, it is necessary to consider the importance of the variables for a project.

\section{Symbols}

PPV - Peak Particle Velocity $(\mathrm{mm} / \mathrm{s})$;

PPA -Peak Particle Acceleration $\left(\mathrm{mm} / \mathrm{s}^{2}\right)$;

PPD -Peak Particle Displacement (mm);

RMR- Rock Mass Rating;

Q-System is a classification system for rock masses with respect to stability of underground openings;

RQD- Rock Quality Designation;

$\xi$ - Damping ratio;

$\Delta \%$ - The difference between field data and numerical result;

$\mathrm{E}_{\mathrm{d}}$ - Dynamic Young's modulus (MPa);

t- time $(\mathrm{s})$;

$\mathrm{D}$ - is the distance from the blasting source to the point of monitoring $(\mathrm{m})$;

$\mathrm{Q}_{\mathrm{c}}$ - is the maximum charge weight per delay;

$\mathrm{K}$ and $\alpha$ are constants that depend on the ground condition as well as the conditions of blasting;

$\mathrm{S}_{\mathrm{D}}$ - Scaled charge explosive;

$\mathrm{KP}$ - distance from the tunnel portal to point of monitoring (m);

R- Multiples' correlation coefficient of regression model;

F- function of variables;

\section{References}

[1] Clayton, E., Soler, B., Voiron, J.,. Renovation of Croix. Rousse tunnel - Specific points of the technical design. AFTES, page 135. Congrès International, Lyon1, 2011. 
[2] Vladimir Feldgun el al,. The Effect of an Internal Explosion in a Tunnel on a Neighboring Buried Structure and Free Surface- The 15th International Symposium on Interaction of the Effects of Munitions with Structures (ISIEMS 15), At Potsdam, Germany, 2016.

[3] Vo Trong Hung, Dang Van Kien. A new research direction on the impact of the tunnel construction explosion shock on the adjacent tunneling structure. Journal of Mining Industry, Issue No.4, pages 78-84, Hanoi, Vietnam, 2017.

[4] J.H. Yanga et al, 2D numerical analysis of rock damage induced by dynamic in-situ stress redistribution and blast loading in underground blasting excavation. Tunneling and Underground Space Technology 70, 221-232, 2017.

[5] Zihan Liu et al., Influence of tunnel blasting construction on adjacent highway tunnel: A case study in Wuhan, China. International Journal of Protective Structures. Volume: 11 issue: 3, page(s): 283-303. Crossref DOI link: https://doi.org/10.1177/2041419619888936. September 1, 2020.

[6] J.H. Yang et al., 2D numerical analysis of rock damage induced by dynamic in-situ stress redistribution and blast loading in underground blasting excavation. Tunneling and Underground Space Technology Volume 70, Pages 221-232, November 2017.

[7] Ao Li et al., Safety Distance of Shotcrete Subjected to Blasting Vibration in LargeSpan High-Speed Railway Tunnels., Article ID 2429713, 14 pages. https://doi.org/10.1155/2019/2429713, Shock and Vibration Volume 2019.

[8] Dang Van Kien, Vo Trong Hung, Do Ngoc Anh. Studying the effects of blasting shock on the lining structure of adjacent tunnels during tunnel excavation by using the blasting method. Journal of Vietnam Construction. Issue No.7, pages 203-207, Hanoi, Vietnam, 2017.

[9] Dang, K.Van. Assessment of the effect of blasting vibration on tunnel lining of Hai Van Pass Tunnel during expanding excavation the auxiliary tunnel by drilling and blasting method (in Vietnamese). Journal of Mining and Earth Sciences. 61, 6 (Dec, 2020), 131138. DOI:https://doi.org/10.46326/JMES.HTCS2020.18. 2020.

[10] Cilsal Murat. The Effect of Geotechnical Factors on Blasting Induced Ground Vibration Particle Velocity. Tunneling and Underground Space Technology 21(3):235235. May 2006.

[11] QCVN 02-2008-BCT. National technical regulation on safety in the process of producing, testing, performing check and acceptance, storage, transportation, use, disposal of industrial explosive materials, and storage of explosive precursors, Viet Nam, 2008.

[12] Dang V.K., Dias D., Do N.A., Vo T.H. (2018), Impact of Blasting at Tunnel Face on an Existing Adjacent Tunnel. International Journal of GEOMATE, July 2018 Vol.15, Issue 47, pp.22-31, 2018.

[13] Lin Da-neng, (2011), The mitigation negative effect of tunnel-blasting-induced vibrations on existing tunnel and buildings, Journal of coal science \& engineering. Pp.28-33, Vol.17 No.1 Mar. 2011. 
[14] Van Kien Dang, Trong Hung Vo, Ngoc Anh Do, The estimation of the vibration effects caused by tunnel blasts: a case study in the croix-Rousse tunnel, Proceedings of the international conferences on earth sciences and sustainable geo-resources development (ESASGD), ISBN: 978-604-76-1171-3, pp: 339-346, Ha Noi, Viet Nam, 2016.

[15] Tran Tuan Minh, Nguyen Quang Huy. Effect of blasting on the stability of lining during excavation of new tunnel near the existing tunnel. Civil Engineering Journal. Vol. 30 No. 1 (2021). https://doi.org/10.14311/CEJ.2021.01.0004, 2021. 